\section{Importância das radiografias de seio frontal para a identificação humana}

\author{
Rhonan Ferreira da Silva ${ }^{1}$, Rodrigo Naves Pinto ${ }^{2}$, \\ Geovane Miranda Ferreira ${ }^{3}$, Eduardo Daruge Júnior ${ }^{4}$
}

\title{
Importance of frontal sinus radiographs for human identification
}

Palavras-chave: antropologia forense, radiografia, seio frontal.

Keywords: forensic anthropology, frontal sinus, radiography.

\section{INTRODUÇÃO}

A identificação humana pode ser efetuada por diversos métodos, sendo a análise das impressões digitais (papiloscopia) o mais utilizado quando os tecidos moles encontram-se preservados. Entretanto, em situações onde o cadáver encontra-se carbonizado ou esqueletizado, uma análise odontolegal ou antropológica pode ser necessária visando à determinação da identidade do indivíduo ${ }^{1}$. Sabendo-se que nos casos de identificação de corpos considerados inicialmente irreconhecíveis, a documentação médica (especialmente as radiografias) pode subsidiar relevantemente nos processos de identificação humana, o presente trabalho tem como objetivo relatar um caso pericial onde restos humanos puderam ser positivamente correlacionados com
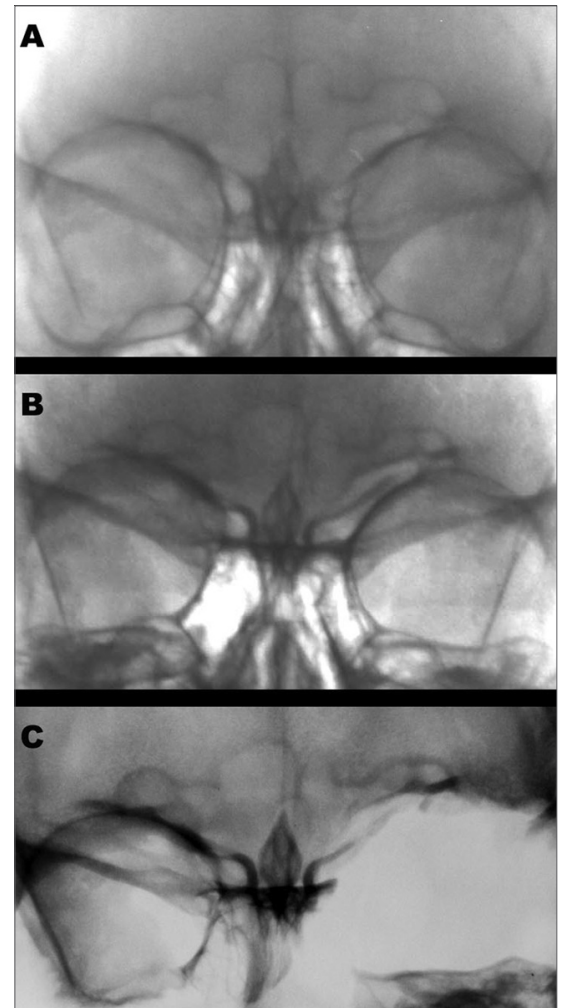

Figura 1. llustra a imagem do seio frontal da vítima em 1989(A) e 1993(B), quando viva, e em 2006(C) pós-morte. a identidade de uma pessoa desaparecida, por meio da análise das imagens do seio frontal, em radiografias póstero-anterior de crânio.

\section{APRESENTAÇÃO DO CASO}

Parte de uma ossada humana foi encontrada em região de mata em dezembro de 2006 , apresentando-se fraturada em boa parte dos ossos remanescentes: ulna, costelas, vértebras, dentre outros. O crânio, também traumatizado e com sinais de carbonização, apresentava apenas a calota superior relativamente íntegra onde praticamente todos os ossos da face e da base estavam fraturados e desarticulados. Numa análise antropológica preliminar foi constatado que o indivíduo periciado apresentava características ósseas típicas do sexo feminino e idade adulta.

As investigações policiais indicaram que a provável vítima seria uma mulher, leucoderma, 30 anos, desaparecida desde maio de 2006. Esta possuía histórico de traumatismo craniano por queda de escada aos 8 anos de idade, com acompanhamento médico até os 25 anos de idade.

Visando determinar se os restos humanos examinados eram ou não pertencentes à pessoa desaparecida, foram entregues aos peritos diversos exames imaginológicos, dentre eles duas radiografias póstero-anteriores de crânio, datadas de 1989 e 1993 (Figuras 1A e 1B). O remanescente craniano foi então radiografado, visando obter parâmetro adequado para subsidiar um confronto antropológico (Figura 1C).

\section{DISCUSSÃO}

Os seios frontais são cavidades pneumáticas forradas por mucosas, situadas entre as lâminas interna e externa do osso frontal ${ }^{2}$. São estruturas radiologicamente evidentes aos 5 ou 6 anos de idade e o seu desenvolvimento completo dar-se-á dos 10 aos 12 anos de idade 3 .

Pelo fato de o seio frontal estar ausente em apenas $4 \%$ da população e possuir variações na forma, área e simetria, este constitui parâmetro importante tanto para a determinação do dimorfismo sexual ${ }^{4}$ quanto para a identificação humana ${ }^{5}$. Para tanto, torna-se imprescindivel que as radiografias póstero-anteriores de crânio sejam confeccionadas dentro dos padrões adequados de processamento, bem como obtidas por meio de técnica empregada corretamente ${ }^{6}$.

\section{CONSIDERAÇOEES FINAIS}

No presente trabalho, foi possível estabelecer positivamente a identidade do corpo esqueletizado como sendo pertencente à vítima desaparecida, pelo fato de as radiografias produzidas em vida terem sido produzidas adequadamente, permitindo a análise da morfologia do seio frontal. As imagens radiográficas foram digitalizadas, e tiveram o brilho/contraste ajustado para melhor visualizar os contornos Os resultados obtidos no confronto entre as radiografias produzidas em vida e pós-morte demonstraram uma convergência nas características analisadas em ambos os lados, apesar de parte da região orbitária esquerda se apresentar fraturada (Figura 1C). Portanto, além de grande utilidade na clínica médica visando identificar traumatismos ou patologias nos seios frontais, as radiografias póstero-anteriores de crânio ainda permitem a visualização da morfologia destas estruturas, subsidiando adequadamente os casos de identificação humana.

\section{REFERÊNCIAS BIBLIOGRÁFICAS}

1.Silva RF, Cruz BVM, Daruge Júnior E, Daruge E, Francesquini Júnior L. La importância de la documentación odontológica en la identificación humana. Acta Odontol Venez 2005;43(2):67-74

2.Schwartz JH. The Skull. Em: Schwartz JH editor. Skeleton keys: an introduction to human skeletal morphology, development and analysis. New York: Oxford University Press; 1995. p. 23-78.

3.Montovani JC, Nogueira EA, Ferreira FD, Lima Neto AC, Nakajima V. Cirurgia das fraturas do seio frontal: estudo epidemiológico e análise de técnicas Rev Bras Otorrinolaringol 2006;72(2):204-9

4.Camargo JR. Estimativa do sexo, através das características radiográficas dos seios frontais [dissertação] Piracicaba (SP). Universidade Estadual de Campinas. 2000.

5.Riepert T, Ulmcke D, Scheweden F, Nafe B. Identification of unknown dead bodies by X-ray image comparison of the skull using the X-ray simulation program FoXSIS. Forensic Sci Int 2001 Mar; 117(12):89-98.

6.Wood RE. Forensic aspects of maxillofacial radiology. Forensic Sci Int 2006 May;159 Suppl 1:S47-55

${ }^{1}$ Mestre em Odontologia Legal FOP/UNICAMP, Perito Criminal Oficial da Polícia Técnico-Científica, GO.

${ }^{2}$ Especialista em Cirurgia Vascular, Médico-Legista da Polícia Técnico-Científica, GO.

Cirurgião-Dentista, Residente em Cirurgia e Traumatologia Buco-Maxilo-Facial DOD/UEM.

${ }^{4}$ Doutor em Ciências, Professor de Odontologia Legal FOP/UNICAMP.

Instituto Médico-Legal da Polícia Técnico-Científica do Estado de Goiás.

Endereço para correspondência: Avenida Aruma Quadra 186 Lote 06 Parque Amazônia Goiânia GO 74835-320.

Este artigo foi submetido no SGP (Sistema de Gestão de Publicações) da RBORL em 24 de dezembro de 2006. cod. 3568.

Artigo aceito em 17 de fevereiro de 2007. 